Ramón Pico Valimaña

Figura 1. Dumbarton Oaks Pre-Columnbian Collection Pavilion, (1958-63). Fuente: Dumbarton Oaks Research Library and Collection

Washington $D C$, AR.DP.MW.PC. 105

Ramón Pico (1966) es Doctor Arquitecto y Profesor Titular del Departamento de Historia, Teoría y Composición Arquitectónicas de la ETSA Sevilla, que a dia de hoy dirige. Visiting Scholar en el Harvard GSD y Profesor Invitado en las Universidades de Lund (Suecia), Nancy (Francia), Politécnico de Milano (Italia), Tongji y SWUST (China). Investigación actual desarrollada como visiting reseacher en Dumbarton Oaks (Washington DC). Premio FAD 2003, premio de la $3^{a}$ Bienal Europea del Paisaje; seleccionado para la VII Bienal de Arquitectura

Española 2001-2002 y también para la exposición Joven Arquitectura Española, en Madrid, otoño de 2008, con itinerancias por Europa y América. Decano del Colegio de Arquitectos de Cádiz entre 2007 y 2011.

\title{
La recuperación instrumental de la Historia en el Pre-Columbian Pavilion de Dumbarton Oaks
}

\author{
Palabras clave: Philip Johnson, arquitectura contemporánea, Dumbarton Oaks, \\ Mildred Bliss. \\ En el contexto de la revisión crítica de la modernidad arquitectónica que se produjo \\ en los cincuenta Philip Johnson destacó como activo defensor de la recuperación ins- \\ trumental de la Historia. El pabellón para la ampliación del Museo de Dumbarton \\ Oaks constituye en este sentido una pieza clave, olvidada o temida por la critica, y \\ en la que su contacto con Mildred Bliss resultaría decisiva. En este trabajo se anali- \\ za esta obra y las vicisitudes de su creación.
}

Eebrero de 1959. Con ocasión de la inauguración de una exposición sobre su obra organizada por un grupo de estudiantes de Yale, Philip Johnson pronunciaría una de sus más célebres sentencias, al indicar que el Estilo Internacional "has lasted from 1923 to 1959" (Johnson 1979c).

Por supuesto, se trataba de un hecho enmarcado en el amplio contexto de la revisión crítica de la modernidad que se venía produciendo desde comienzos de los cincuenta, en la que Johnson destacó sin duda como el más franco defensor de la

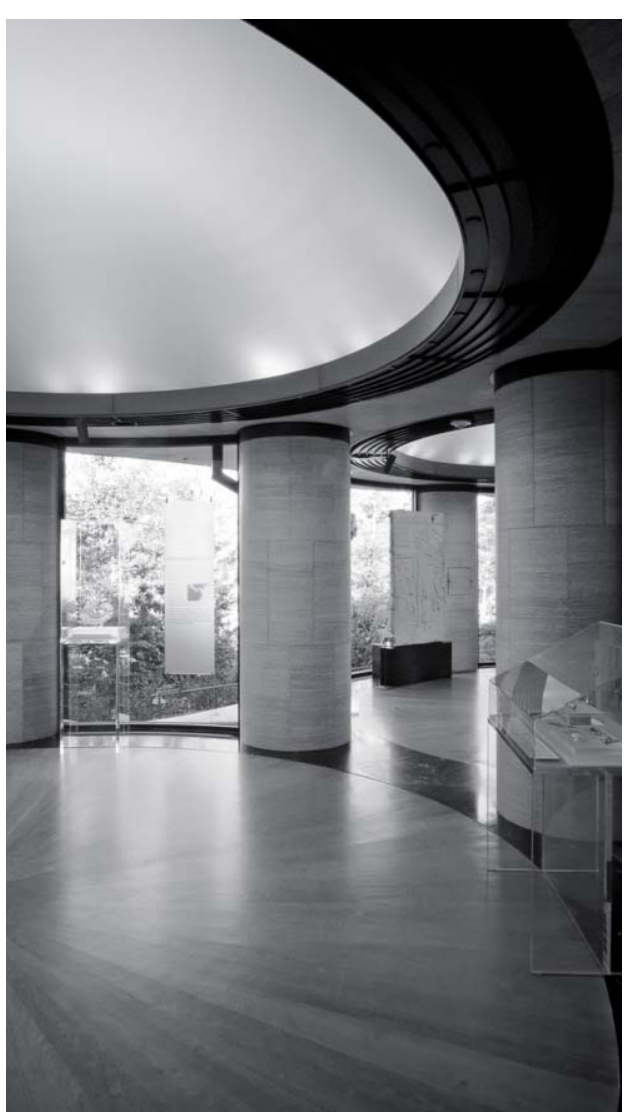

recuperación instrumental de los valores de la arquitectura histórica. Una voz especial en el amplio coro que contribuyó a desmontar la tiranía del dogmatismo moderno (Hitchcock 1951, Saarinen 1953, Gropius 1954).

Esta actitud volátil, mantenida con constancia a lo largo de su larga carrera, le acarrearía críticas dispares. Probablemente, Philip Johnson sea uno de los arquitectos contemporáneos que más disparidad de calificativos atesora. Para la gran parte de la crítica, simplemente un ecléctico (Lambert 2009:197); para sus más cercanos, un evolucionista, demasiado impaciente a veces, pero genial catalizador de los saltos de la arquitectura contemporánea (Stern 2009); para muchos un traidor, el mejor imitador de Mies; para el recuerdo, un arquitecto banal o caprichoso..., para él, simplemente una puta ${ }^{1}$. Abierto, receptivo, siempre dispuesto a satisfacer las demandas del tiempo, su tiempo, como cliente.

Desde esta perspectiva, más que sentenciar a su hijo, al indicar 1959 como cierre del Estilo Internacional, Johnson lo lanzaba a una carrera en busca de la madurez, de una renovada identidad sólo posible a través del cambio permanente, de la renovación de sus instrumentos, asimilando las lecciones de filosofia de Rusell, siguiendo la corriente de aquel río de Heráclito que tanto le cautivara: Panta Rei (Vyas 1996:50-56, 2009).

\section{Hurray for History!}

Efectivamente, en aquella conferencia pronunciada en Yale, que tomo el elocuente título de Whither Away- Non-Miesian Directions, Johnson acabó declarándose profundamente tradicionalista: "My passion is history. I pick up anything, any old 


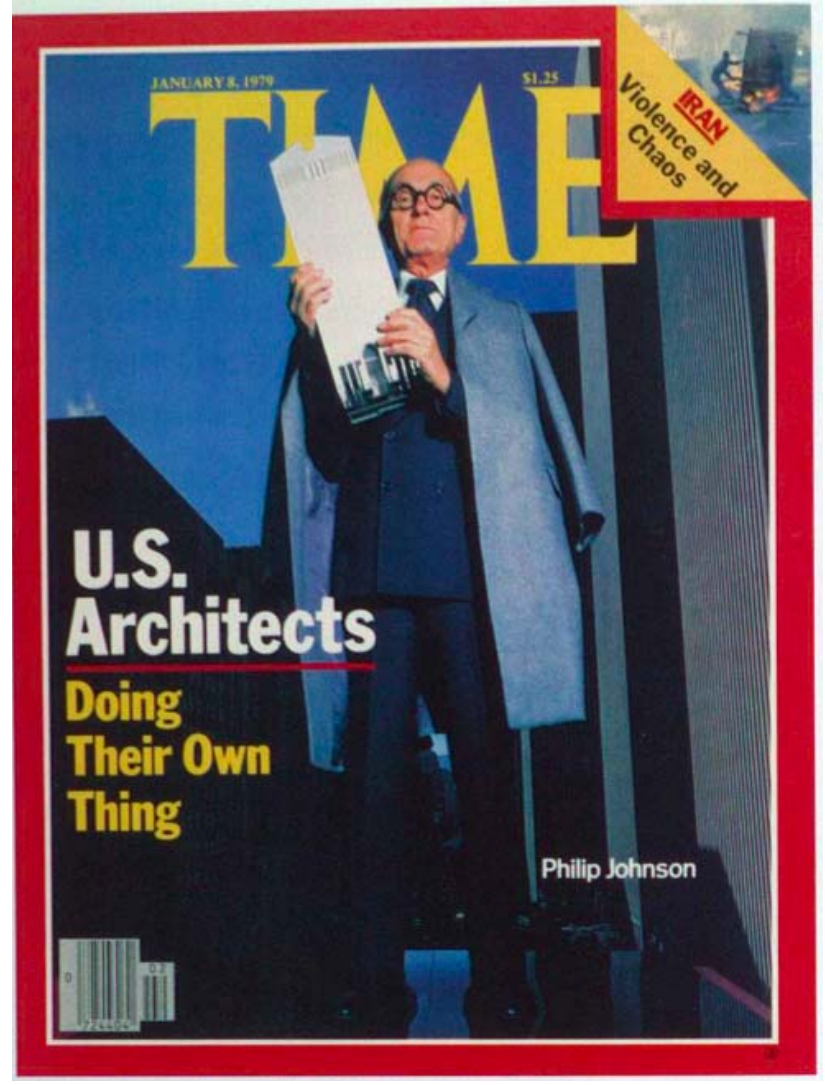

Figura 2. Portada de la revista Time, 8 Febrero 1979.

Figura 3. Jury en la School of Architecture. Yale University Art Gallery, 1960. En primera fila, de izquierda a derecha: Philip Johnson, Paul Rudolph, and Vincent Scully.

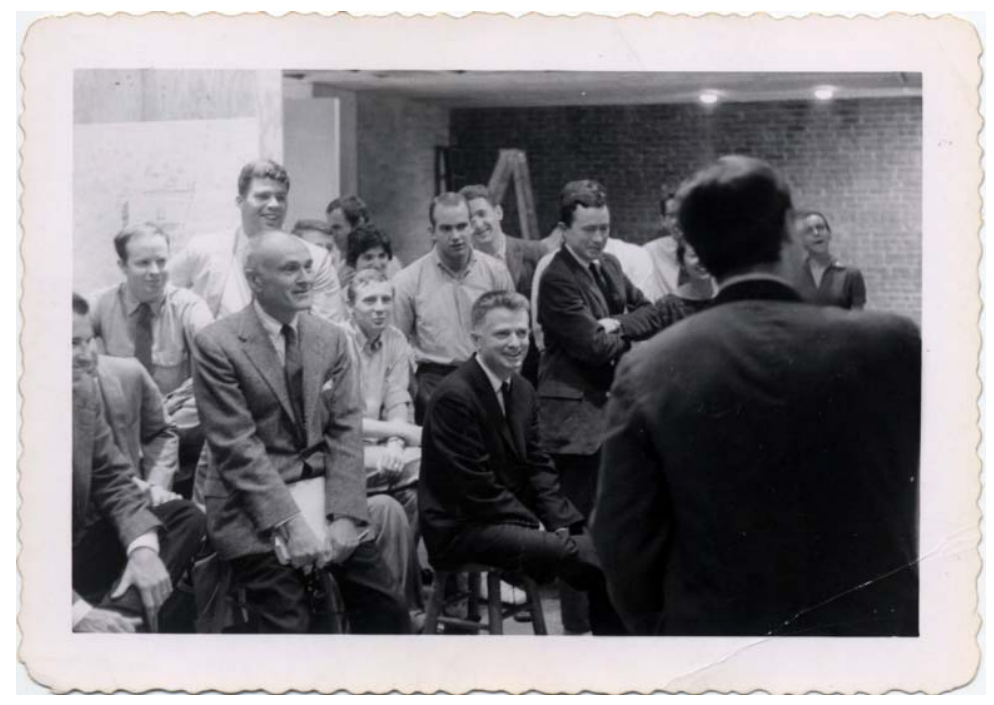

arquitectura histórica.

Una reivindicación consolidada por sus frecuentes viajes a Europa y Oriente Medio durante este periodo y en su impaciente atracción por determinados iconos clásicos como Villa Adriana (Scully 2009:25). A mediados de la década su posición tradicionalista era nítida, como reconoció en 1954 con ocasión de una clase en Harvard, posteriormente recogida en Perspecta como The Seven Crutches of Modern Architecture, en la que intentaba desmantelar los siete temas centrales en la metodología de la arquitectura moderna.

En él se quejaba de la falta de interés por la Historia, que había dejado de ser una de las muletillas con las que defender la validez de los proyectos, y reivindicaba una mirada permanente al pasado, extendido hasta el trabajo de las generaciones inmediatamente anteriores: "(we) can look back to the shapes we leave here and get the same thrill that I get in looking back at theirs-at the Parthenon, at Chartes Cathedral".

Una mirada libre, un entendimiento de la Historia de la Arquitectura como caja llena de útiles herramientas que necesitaban de conocimiento y pericia para alcanzar su máximo rendimiento: "I believe in history. I mean by tradition the carrying out, in freedom, the development of a certain basic approach to architecture which we find upon beginning our work here".

El fin de la tiranía de los estilos sería asî uno de los grandes valores de la revolución provocada por la arquitectura moderna, al permitir pensar en la tradición como una oportunidad para la permanente evolución y nunca más como una rémora. Pasado como sostén de la construcción del futuro, en este sentido, decia: "I am a traditionalist".

A lo largo de la década de los cincuenta un nutrido grupo de artículos y conferencias le permitieron profundizar en esta posición y hacer proselitismo por academias y grupos profesionales: Estilo y Estilo Internacional (Barnard College, 1955), Retirada desde el Estilo Internacional a la situación presente (Yale, 1958), El Estilo Internacional: muerte o metamorfosis (MOMA, 1961).

En pleno éxtasis de su conversión tradicionalista, Johnson recibiría el encargo de un pequeño pabellón para la ampliación de Dumbarton Oaks, el Museo que Mildred Barnes Bliss y su marido Robert Woods Bliss modelaban con cariño desde 1920 en la periferia de Washington. 
Figura 4. Milton Latour Grigg. Alzado y sección de la propuesta de ampliación del Museo de Dumbarton Oaks, 1958. Fuente: Dumbarton Oaks Research Library and Collection,

Washington $D C$ (AR.AP.MW.GL.114).

Figura 5. Ernest Clegg. Vista aérea en acuarela de Dumbarton Oaks, 1933. Fuente: Dumbarton Oaks Research Library and Collection, Washington DC (AR.DG.GE.002).

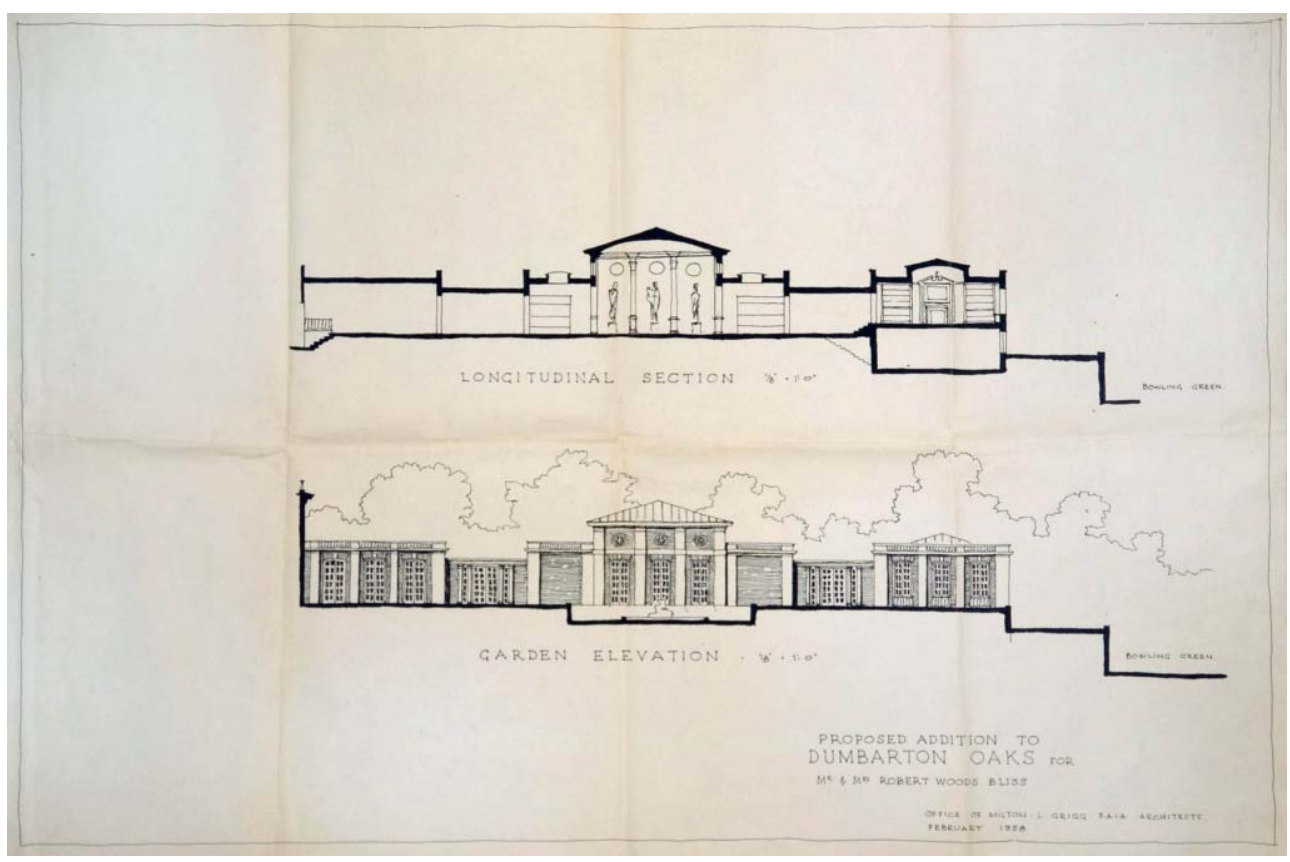

\section{La Dama}

Mildred Bliss encarnaba a la perfección el modelo de mecenas que Johnson anhelaba, la relación de ambos se avivó hasta el punto de reconocerse como amantes intelectuales: "Mrs Bliss and I were in love" (Tamulevich 2001:18). En continuo tránsito vital entre el viejo y el nuevo mundo desde su juventud; integrada por igual en la cultura europea y la americana; amante del mundo clásico pero reconocedora de los valores del arte contemporáneo; con dinero suficiente para dar alas a la sofisticación material que Johnson buscaba en su obra, ${ }^{2}$... la señora Bliss sería la cómplice perfecta para confirmar su giro intelectual y profesional.

Durante su continuo periplo diplomático junto a Robert su fascinación e interés tanto por el mundo bizantino e islámico como por la jardinería había ido creciendo. En este sentido resultaría decisiva la

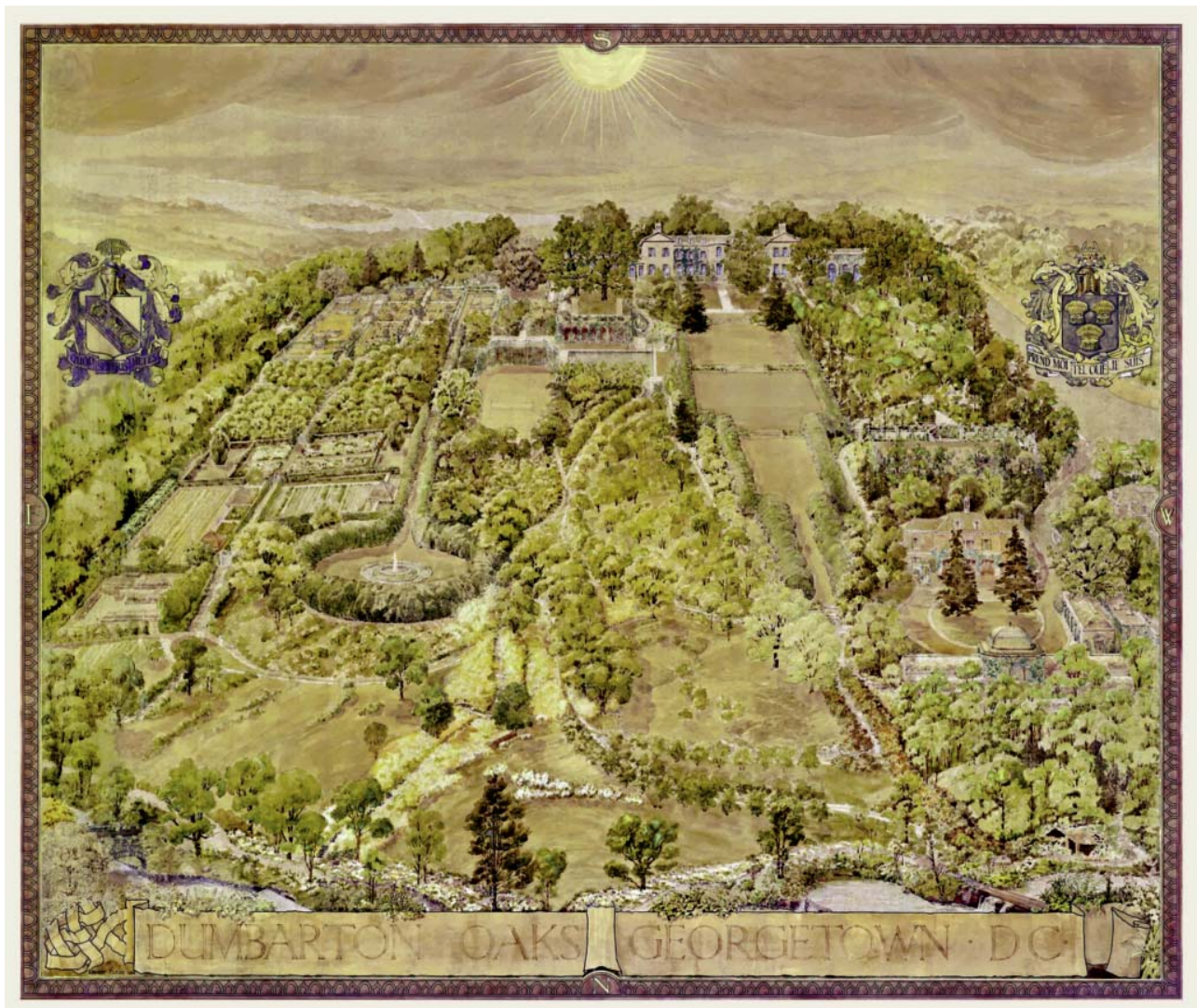


influencia de Royall Tyler, quien a través de una prolongada relación epistolar inoculó en Mildred el amor por las culturas medievales y los jardines.

Su carácter impregnó todos los rincones de Dumbarton Oaks, cada esquina cada terraza, cada paseo, cada jardin,.... siempre apoyada en los profesionales, en los que confiaba plenamente. Johnson recordaba: "I had my partner, Mrs. Bliss. I thought it should be the firm of Johnson and Bliss".

Los Bliss llevaban varios años intentando acomodar entre las paredes del pequeño museo su creciente colección de monedas, estelas y textiles bizantinos a los que se iban a sumar la cuidada selección de incunables de botánica y jardinería de Mildred, y la nueva pasión de Robert: el arte precolombino. La ampliación resultaba inevitable, aunque implicara que el jardín cediera terreno a la arquitectura (Carder 2012).

Tras una primeras tentativas producidas en 1952 de la mano del arquitecto neoyorquino Frederic King, que confirman la previsible filiación historicista y neopalladiana de los Bliss, en 1958 el encargo se reorienta y Johnson entra en escena.
Quizás la mediación de su común amigo el artista y escritor Lincoln Kirstein, o tal vez el contacto directo en las sesiones del MoMa, del que en 1957 Johnson había sido nombrado Director de Arquitectura, permitieron este encuentro. ${ }^{3}$ Sea como fuere, Johnson recibe, en paralelo a Milton LaTour Grigg, el encargo del diseño de un pabellón para la ampliación del Museo. ${ }^{4}$

Se produce entonces una clara disputa entre dos arquitecturas que miraban a la Historia de forma radicalmente opuesta. La de LaTour Grigg enfatizaba una fachada neopalladiana de ladrillo y caliza, adornada con ojos de buey y detalles georgianos, en un intento de armonizar vía estilo con sus inmediatos vecinos. La propuesta de Johnson, simplemente, no tenía fachada. Se ocultaba entre los árboles para crear un espacio cargado de Historia, lo que provocó primero el asombro y finalmente la total rendición de Thacher. ${ }^{5}$

$\mathrm{El}$ peso y la riqueza del pasado, materializado en las dispares colecciones que el Museo atesoraba, y la potencia del paisaje de Dumbarton Oaks, modelado durante más de treinta años por Mildred junto a la paisajista Beatrix Farrand como auténtico
Figura 6. Robert Ruzicka, Plano de los jardines de Dumbarton Oaks, 1935. Fuente: Dumbarton Oaks Research Library and Collection, Washington DC (AR.DG.GE.004).

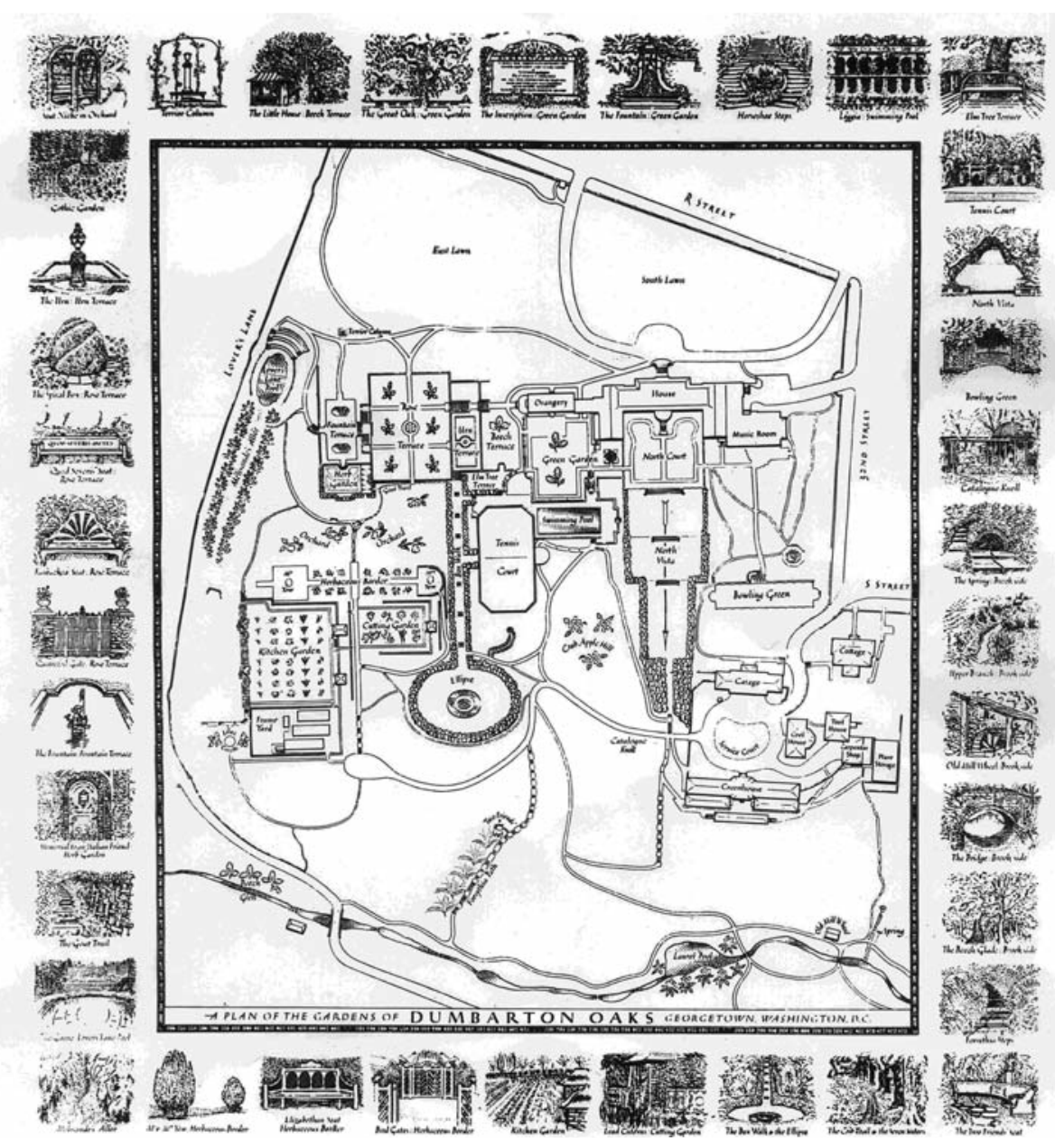


Figura 7. Philip

Johnson. Planta de la ampliación del Museo de Dumbarton Oaks, 27 Agosto 1959.

Fuente: Dumbarton Oaks Research

Library and

Collection,

Washington $D C$

(AR.AP.MW.PC.OO1).

Figura 8, Philip

Johnson. Situación en el Bosque. Ampliación Museo Dumbarton

Oaks, 3 Abril 1960. Fuente: Dumbarton Oaks Research Library and

Collection

Washington $D C$ (AR.AP.MW.PC.005).

Figura 9. Ilustración de Philip Johnson 1949-65 (1966). p. 90.

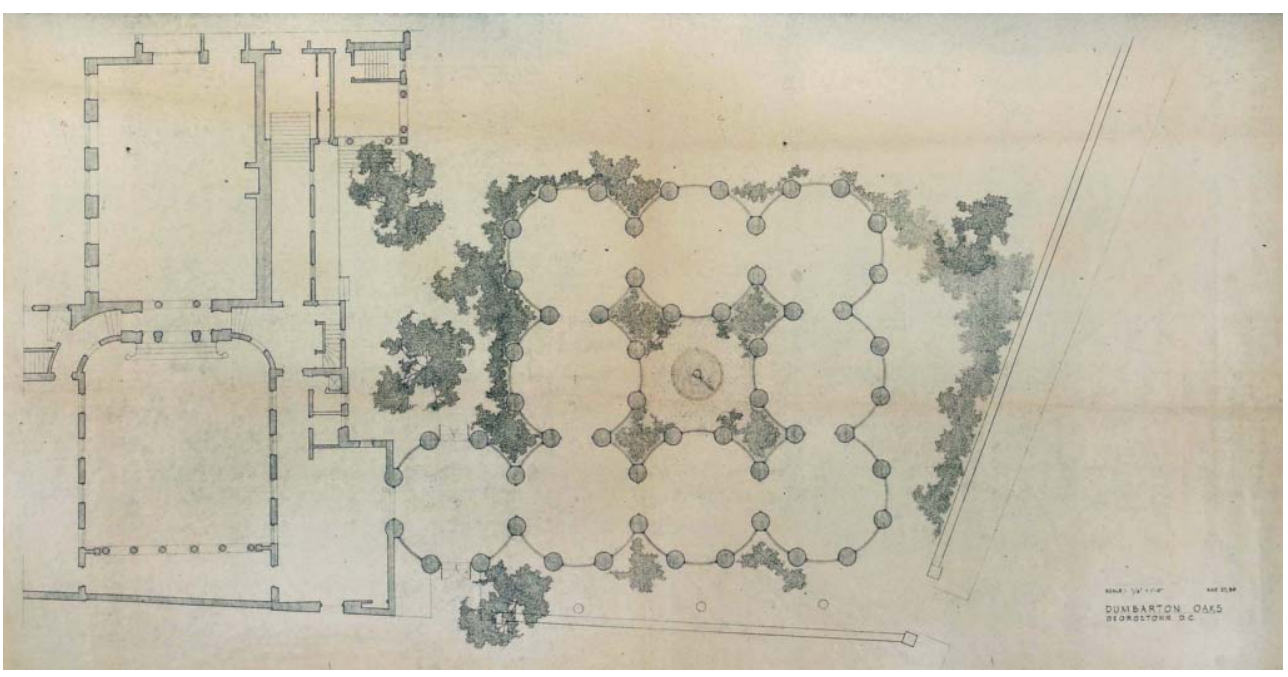

homenaje a la jardinería clásica (Tankard 2009), convertian a este lugar en el escenario perfecto para encarnar el reencuentro de Johnson con la Historia y la Naturaleza.

\section{Y el 'Bosque'}

Las dos ubicaciones que se barajaron para la ampliación, a norte y sur del Museo, compartian la existencia de una densa arboleda, ${ }^{6}$ cuyo tratamiento propiciaría un doble viraje: para Johnson supondría dejar atrás la imagen exterior del edificio, que desaparecía envuelto por la vegetación; para Bliss, la renuncia al diseño de un nuevo jardín y la puesta en valor del arbolado existente.

Efectivamente, ya desde las primeras propuestas $^{7}$ Johnson renuncia a que su edificio tenga presencia en el conjunto construido para integrarse en la vegetación: "The building was to became a part of the Bosque, with the trees growing right up next to it" (Johnson 2001). Como se manifiesta claramente en la grafia de los planos, el edificio queda prácticamente oculto al visitante y se descubre fundamentalmente como espacio interior, del que tan sólo asoma la apertura del nuevo acceso desde la calle

En esos primeros planos, e incluso en la maqueta que los acompañaba, cobra especial fuerza expresiva la masa vegetal que envuelve a la arquitectura y la completa en sus vacios interiores. Una masa indefinida en tamaño o especies, pero destacada en el conjunto como piel, envoltorio de un espacio hueco. A medida que el proyecto toma forma, las especies vegetales van encajando y los planos de identificación y posición de cada uno de los ejemplares se prodigan en detalles, apuntalando la apuesta: "The trees were absolutely sacred, to her as well as to me, and I used every tree". 5 Cuando finalmente la obra acabada se publica con cuidadosos grafismos, la presencia de los elementos vegetales llega incluso a acentuarse, reforzando esta idea.

En la presencia del patio se deduce una cierta influencia de Bliss, a quien Tyler habría enseñado a apreciar estos espacios. Resulta ilustrativo analizar cómo, del desdén con que describe el patrimonio sevillano, Royall Tyler escasamente salva los jardines del Alcázar y el ambiente de los
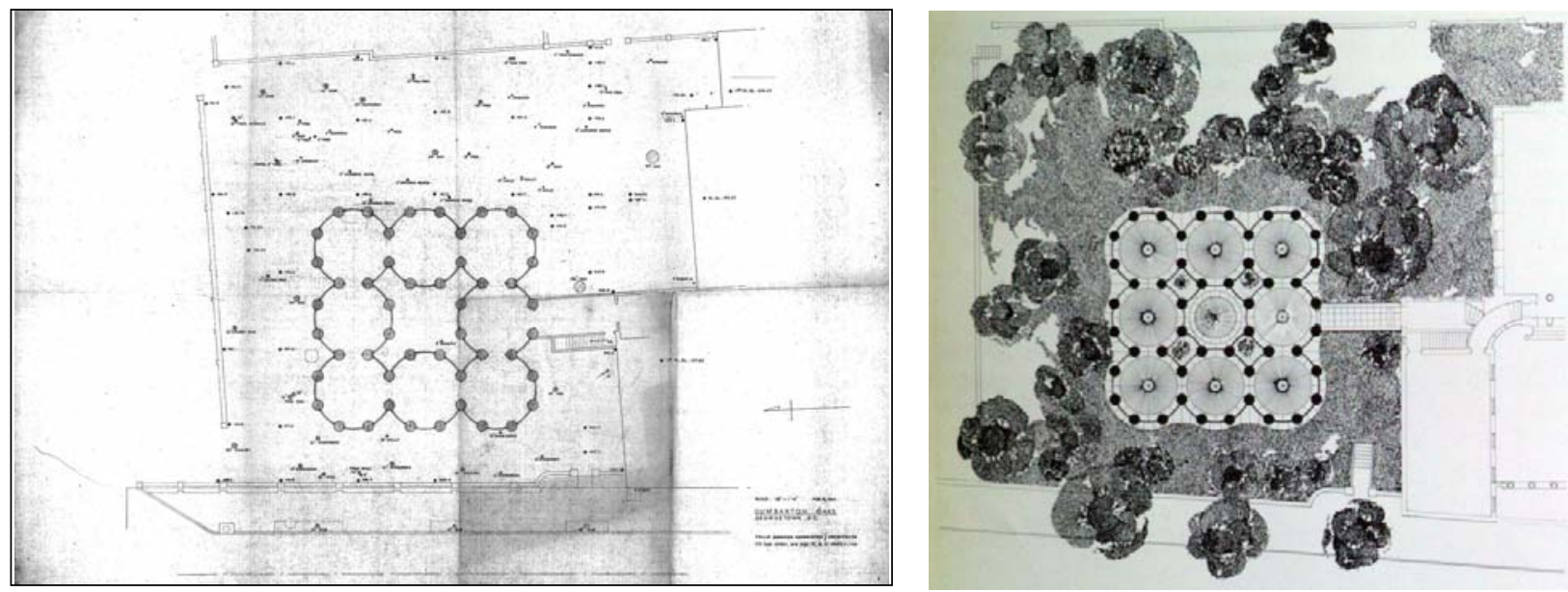


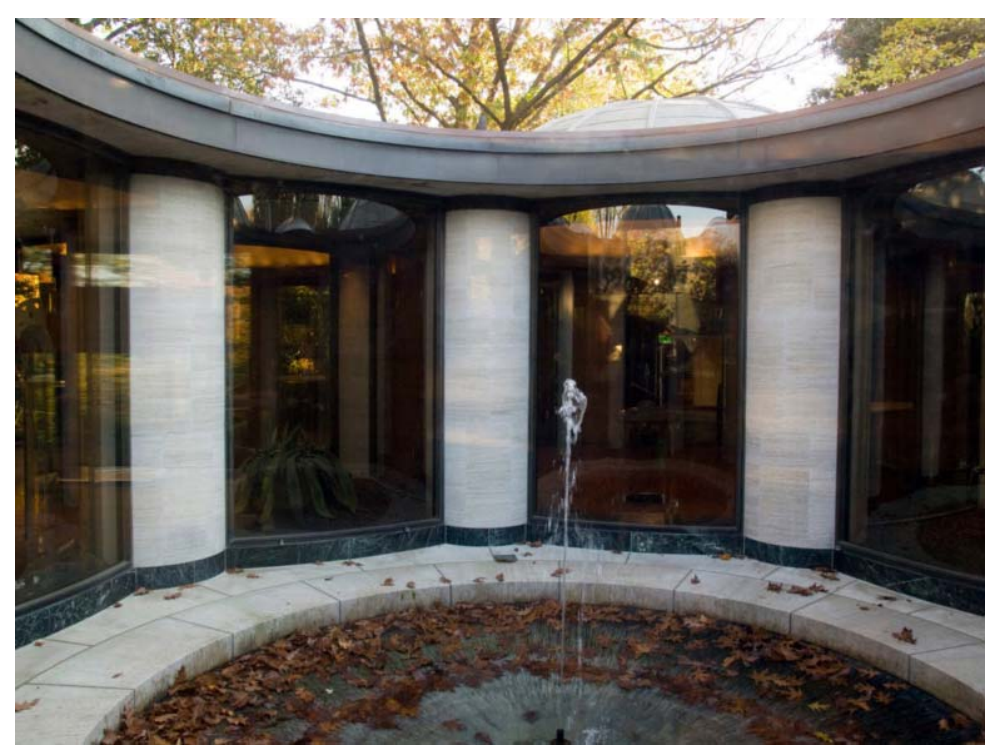

Figura 10. Estanque de pizarra y fuente en el patio (Dumbarton Oaks Research

Library and Collection,

Washington DC (AR.DP.MW.PC.042).

Figura 11. Philip Johnson. Planta baja, propuesta preliminar. Ampliación Museo Dumbarton Oaks, 7 Enero 1960 (Dumbarton Oaks Research Library and Collection

Washington $D C$ (AR.AP.MW.PC.066).
Revela también el proyecto un cambio de actitud en Beatrix Farrand, la paisajista que modelara junto a Mildred Bliss los jardines del conjunto: la plucra pero expeditiva jardinería clásica daría paso a una interpretación más abierta que permitiría el respeto del 'Bosque'. Así, de una propuesta de 1958 en la que la ampliación planteada por LaTour Grigg arrasa todo el entorno para organizar un jardín italiano, se pasaría a esta posición de diálogo con la vegetación espontánea.

\section{Simplemente un vacio}

Desde el momento del encargo Johnson recibiria de Dubarton Oaks datos concretos sobre carácter y dimensiones de los contenidos, sugiriéndose ya entonces que el pabellón debería albergar una muestra heterogénea en la que los mosaicos bizantinos convivirian con las nuevas piezas de la colección precolombina: "Thinking of mosaics reminds me of the fact that if all of the Byzantine objects are to be in the new wing, the four mosaics now in the floors of the various corridors would have to be moved". 10 Pero finalmente el tamaño de las colecciones y unos razonables criterios museográficos llevaron a encaminar su uso exclusivo como joyero, como a Mildred le gustaba llamar al Pabellón, de las piezas precolombinas.

No parece sin embargo que Johnson hiciera mucho caso a estas circunstancias. Para él, el encaje preciso del contenido pasó a un segundo plano, a merced de la definición del espacio y su relación con la envolvente natural, si hacemos caso a sus recuerdos:

"I didn't really know what was going to be exhibited in the museum. As a

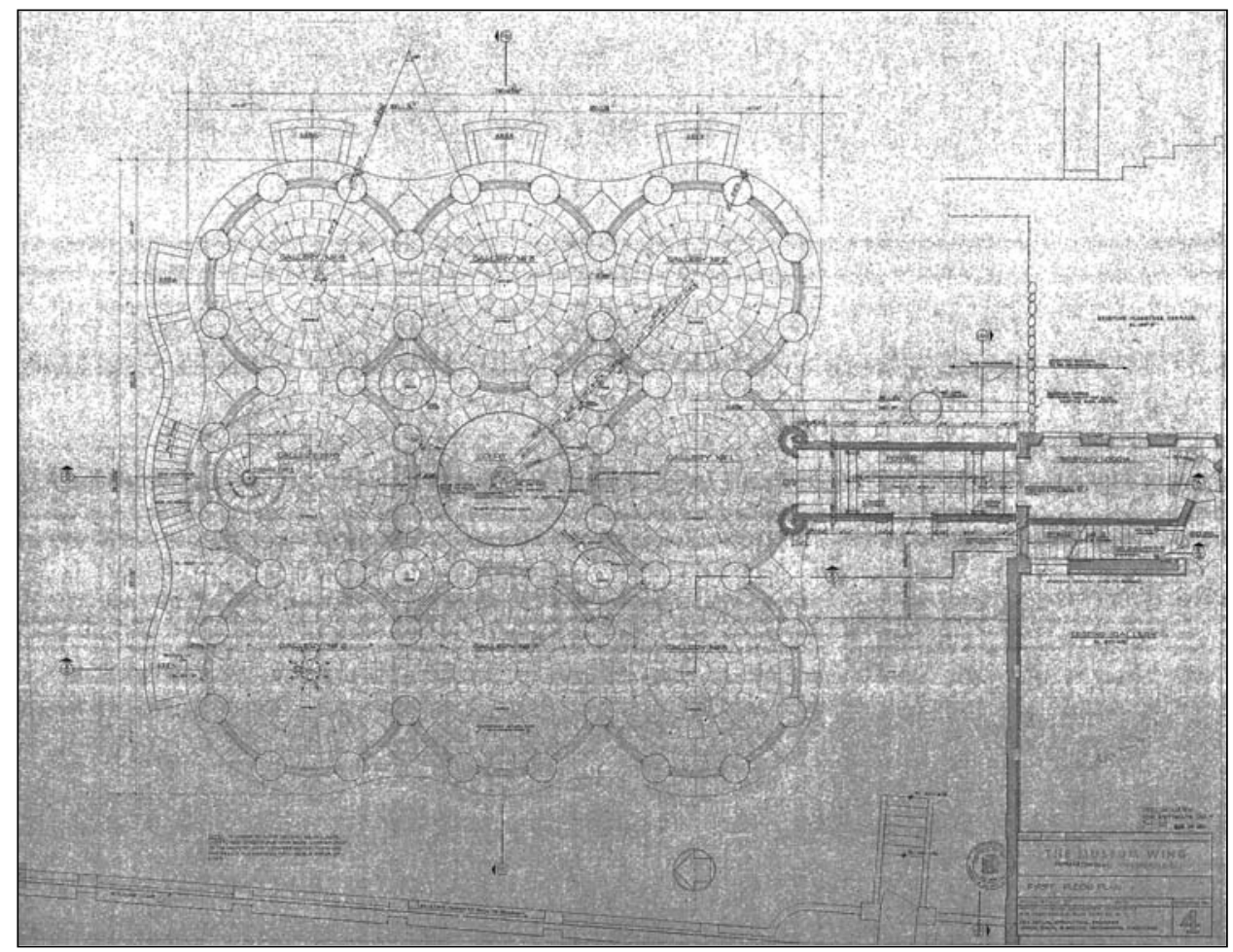


Figura 12. Philip Johnson. Sección constructiva preliminar. Ampliación Museo Dumbarton Oaks, 4 Enero 1960. (Dumbarton Oaks Research Library and Collection,

Washington $D C$ (AR.AP.MW.PC.062)).

Fig 13, El pabellón en obras, son la cubierta de hormigón descansando en esbeltos pilares metálicos, 27 Febrero 1962.

Fotógrafo: Stewart Bros. Fuente:

Dumbarton Oaks Research Library and Collection,

Washington $D C$ (AR.PH.MW.PC.FP. O16).

Fig 14, El pabellón en obras: la cubierta de hormigón recibe su revestimiento definitivo, 31 Mayo 1962. Fotógrafo: Stewart Bros. Fuente: Dumbarton Oaks Research Library and Collection,

Washington DC (AR.PH.MW.PC.FP 021)). museum curator, which I was at the time, I should have realized that the building should have been a background to the objects" (Tankard 2009)

De esta manera el proyecto queda resumido en la construcción de un claro artificial en el bosque, un vacío en el que alojar un edificio funcionalmente versátil, basado en la articulación de unos módulos de planta circular. La disposición de éstos, especialmente en esta primera propuesta, recuerda más a una estructura crecedera, en racimo, que a una cerrada planta de arquitectura bizantina, como reconoce Johnson:

"we stuffed our functions in those days into preconceived geometric volumes. The cube, the cylinder, the rectangular solid. Or even into warped shapes or bunch of grape clusters, my Dumbarton Oaks being one example". (Johnson 1965)

En la propuesta inicial Johnson situaba el pabellón al Sur del edificio existente, empleando uno de los módulos cupulados como acceso y unión con la esquina noreste. Cuando finalmente en 1958 Thacher entendió necesario dividir el programa, escindiendo Garden Library y colección Pre-Colombina, el hecho apenas tiene efecto sobre el proyecto. La propuesta resultante, que pasa al Norte del Museo existente, mantiene la filosofia: envoltura vegetal, secuencia de módulos cupulados, patio central, tan sólo la presencia de un notable ejemplar de roble provocó una importante distorsión, de la que Johnson pareció arrepentirse: "One of them, I honored in particular more tan I should have - the tree where the pas-

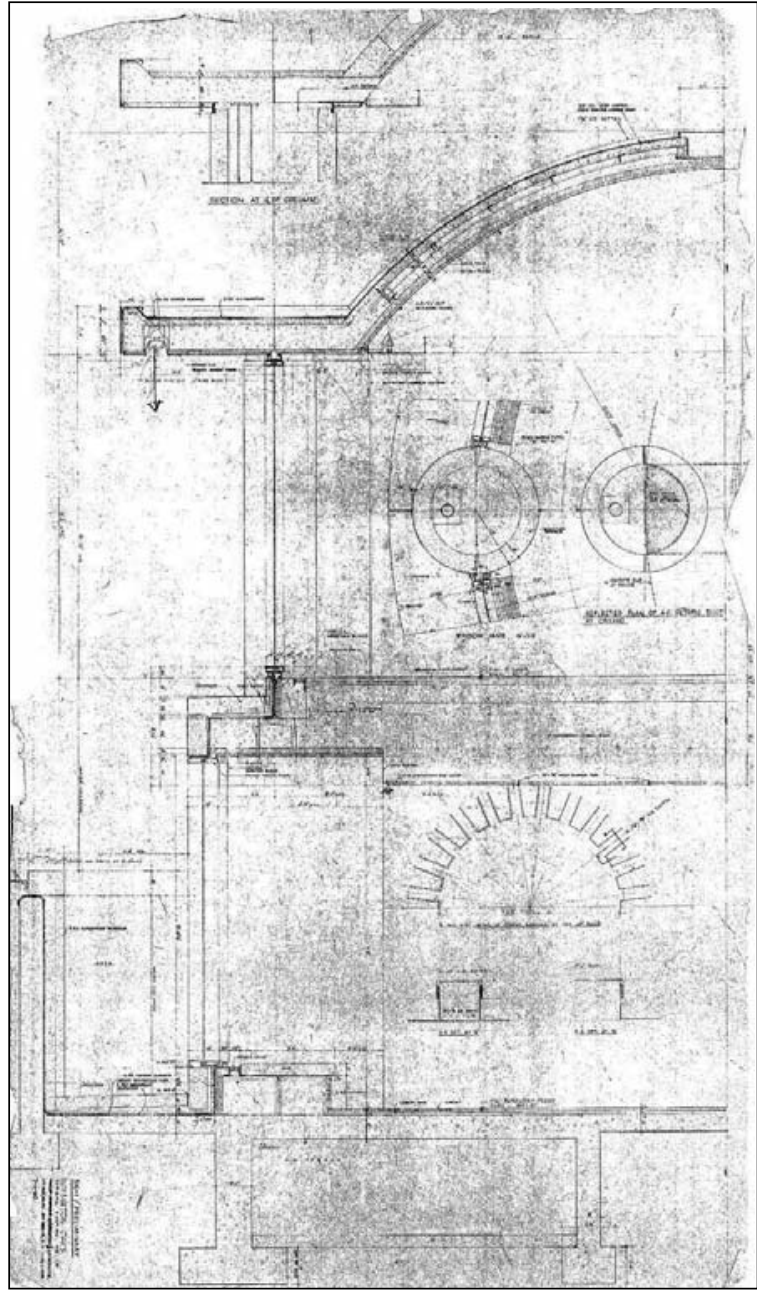

sageway was to go between the new and the old buildings". Efectivamente, el respeto a este árbol conllevaria la desaparición del módulo que en el proyecto inicial establecía la conexión con el edificio existente, en lo que a la larga se convertiria en uno de los gestos más torpes del proyecto por la absurda manera de resolverlo.

Pero la modulación no resulta suficiente, Johnson buscaba algo más en su proyecto, y la Historia vendría en su ayuda:
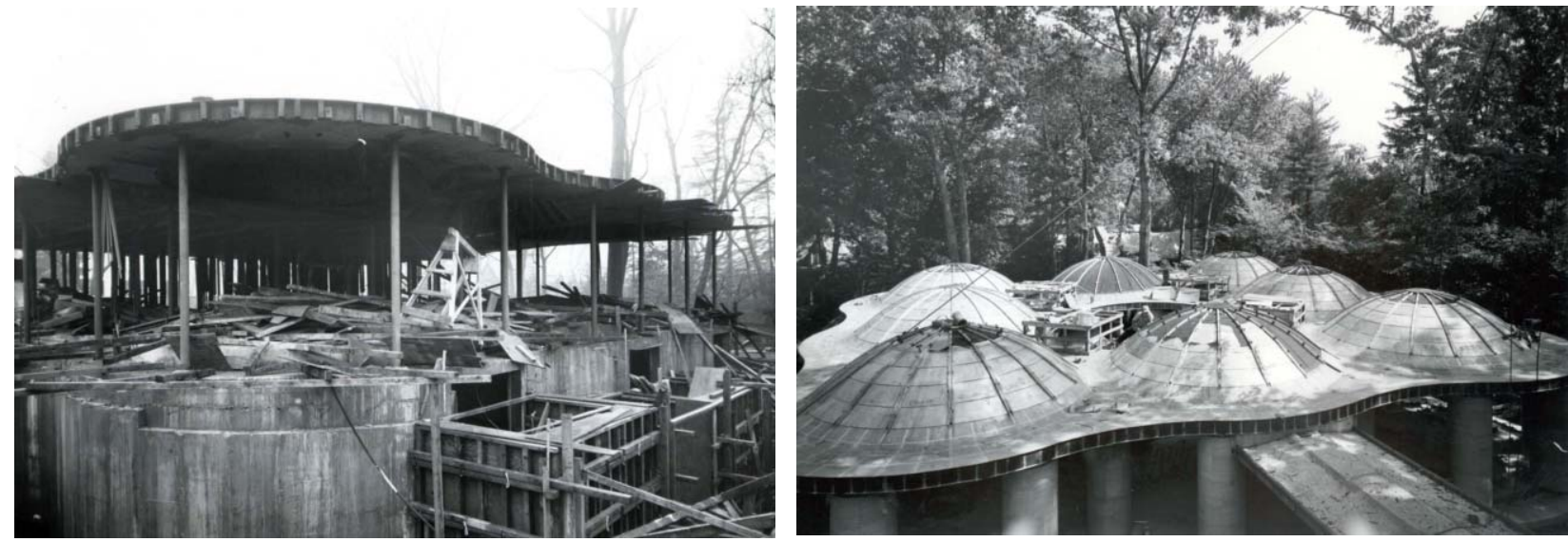


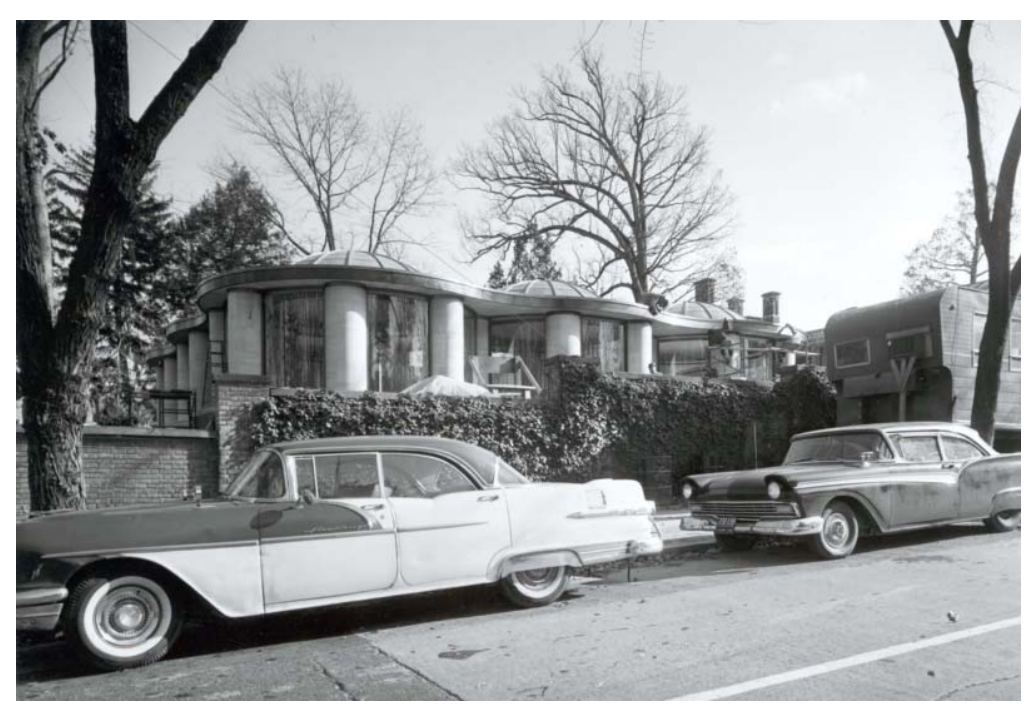

Figura 15. Exterior de la obra tras su finalización, 26 Noviembre 1962. Fotógrafo:

Stewart Bros. Fuente: Dumbarton Oaks

Research Library and Collection,

Washington $D C$ (AR.PH.MW.PC. FP.033).

Figura 16. Philip Johnson. Dormitorio del Pabellón de invitados en New Canaan (1953).

Fig 17. Philip Johnson. Central Nuclear de Rehovot, Israel (1960). "there are buildings of extremely subtle and modulatory relations [...] The result is a magnificent plan. But it doesn't satisfy. It does not do us emotionally enough good anymore just to see buildings well related in blocks. Here again, what history can do for us! Think, for example, of the plans of Roman army camps (Timgad) Hellenistic squares (Assos), St. Peter's, St. Mark's". (Johnson 1979c)

\section{El deleite de la forma, sin importar su origen}

La crítica, que durante años eludió el pabellón, apenas se refirió a él mas que por su más inmediata apariencia: la influencia bizantina e islámica. Ésta sin duda le serviría a Johnson para encender la conexión con Mildred Bliss: "Mrs. Bliss was just delighted that I thought of that [the Byzantine/Islamic historical reference]" (Lewis, O־Connor 1994:54).

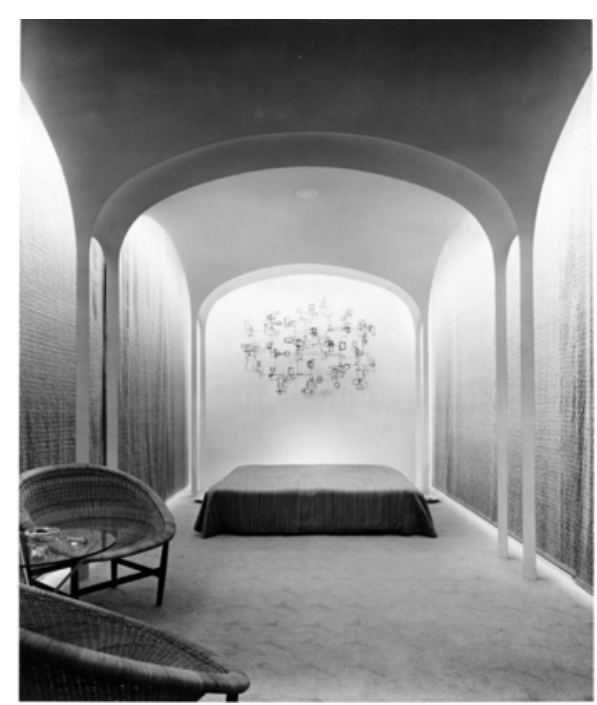

Pero el pabellón atesora muchas más lecturas: el Templo de Vesta, Lutyens, Borromini, o Wright también se dan cita en la obra, dando cuenta de ese Panta Rei en busca de la pureza de la forma, dejando atrás irremediablemente al Estilo Internacional, que para entonces ya se había convertido en su cabeza de turco:

"The duty of the artista is to strain against the bonds of existing style -in our case the International Style - and only this procedure makes the development of architecture posible ... So now the flood gates are open to the delights of pure form, whatever its origin. Anything goes". (Rodman 1957:54)

Sólo cabe entender el pabellón como reflejo sintético de la diversidad de intereses que en los años inmediatamente precedentes se dieron cita en su obra y punto original de una nueva manera de componer la modernidad.
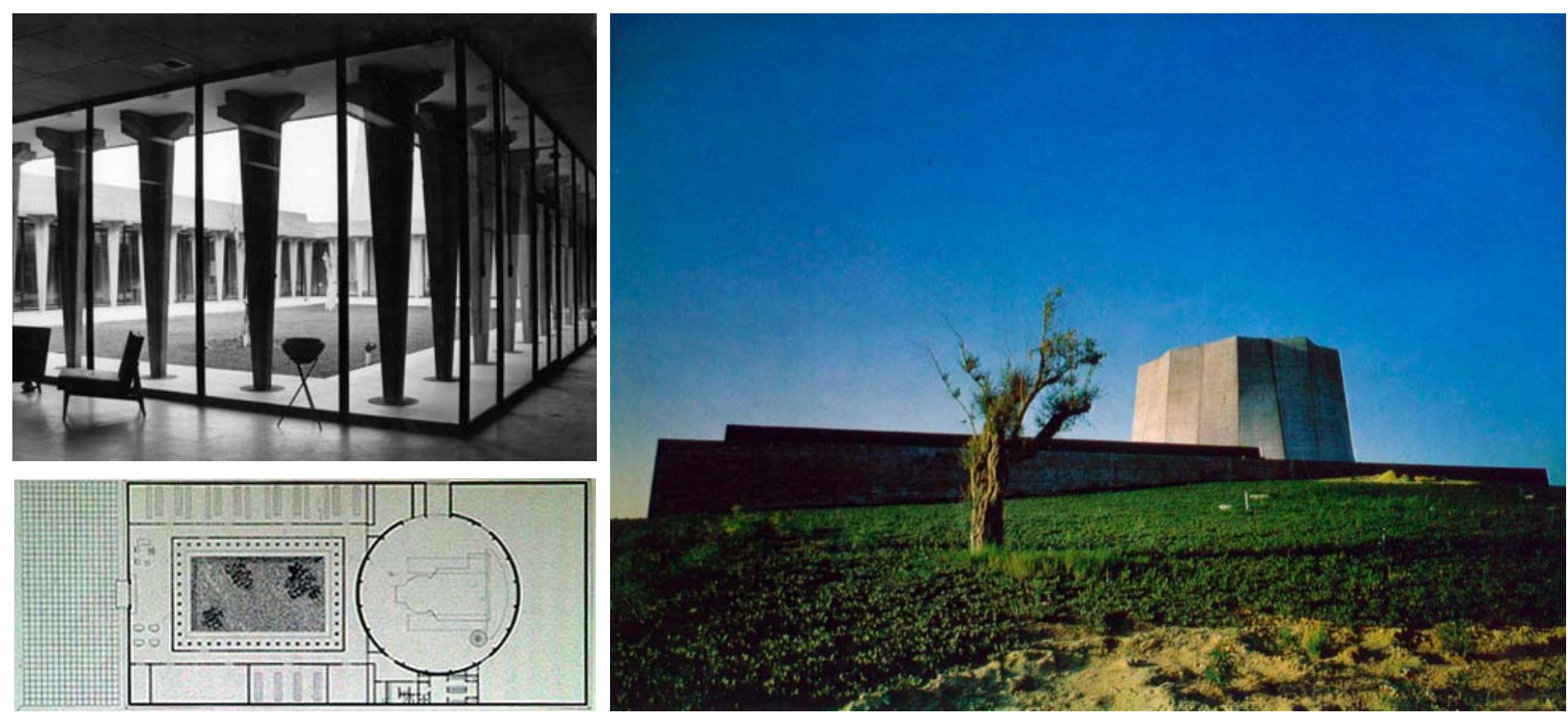
Fig 18. Exterior del Pabellón de Dumbarton Oaks. Fuente: Dumbarton Oaks Research Library and Commelction, Washington $D C$, PC.J.054.

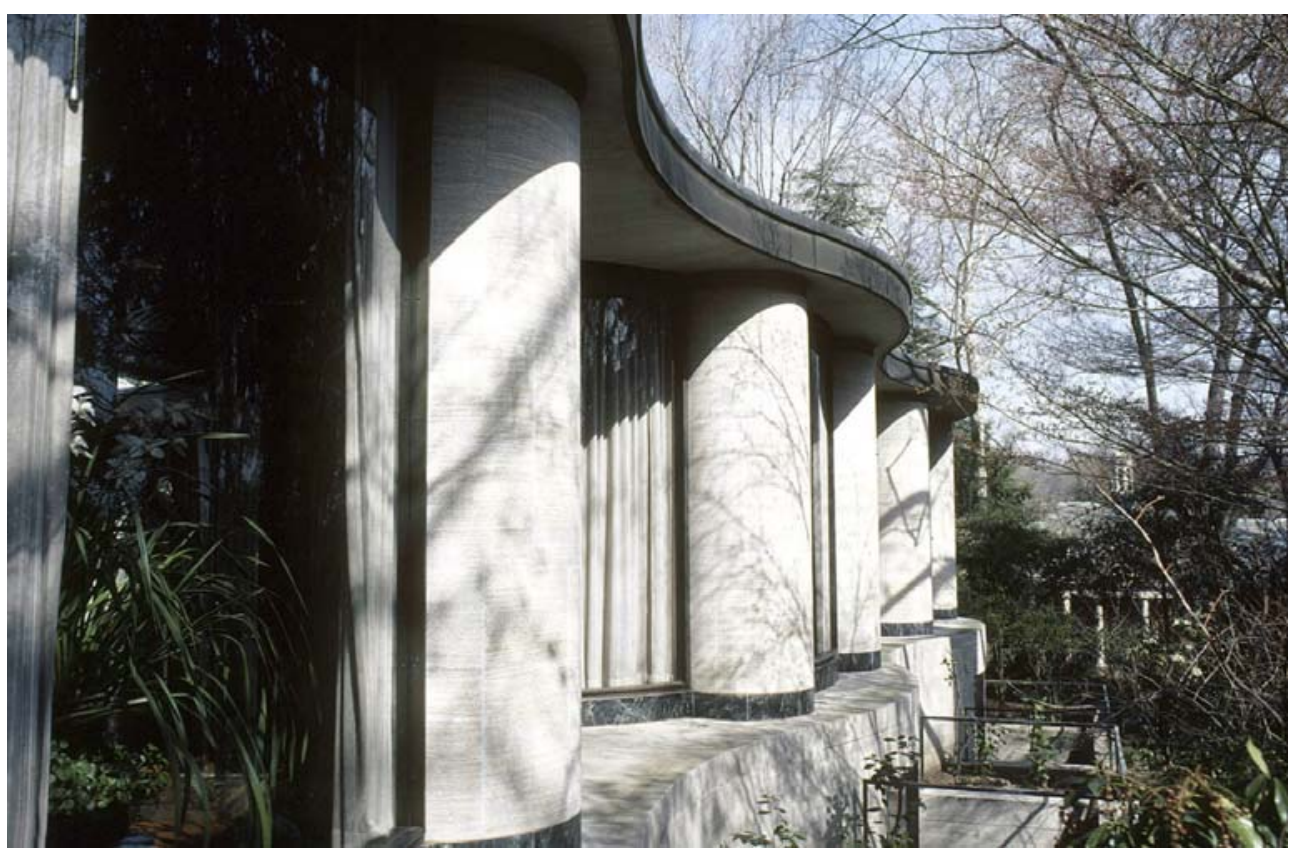

Ya en 1953 Johnson habia sorprendido con los ecos clásicos que reflejaba el techo abovedado de su casa de invitados en New Canaan, "my first break from the International Style" (Lewis, O'Connor 1994:37), amplificados al año siguiente en la Sinagoga en Port Chester, en la que Scully denota la clara de influencia los pequeños baños de la Villa Adriana, llevando al extremo la sensación de cuerpo flotante de las bóvedas romanas.

Otras fuentes, etruscas, renacentistas, neoclásicas o egipcias (Cook, Klotz 1973:28) fueron también encontrando su sitio en el abanico de referencias dispuestas a sumarse a las de los grandes maestros de la modernidad, desde una mirada inclusiva a la Historia "As you see, I dont have this prejudice about today. To me there is no today. To me there is just wonderful things and not wonderful things" (Lewis, O`Connor 1994:47). Así, bien de una manera reflexiva o simplemente a través de su background latente, irian surgiendo obras igualmente dispares, al arte o la guerra, como la Galería de Pintura de New Canaan o la Central Nuclear de Rehovot en Israel (Lambert 2009).

Desde esta perspectiva, el joyero sería una pieza relevante en la comprensión de las transformaciones de la arquitectura de los cincuenta, una evolución sofisticada de su Glass House en la que el cerramiento de vidrio se ablanda para ondularse en un gesto barroco. Una obra contemporánea cargada de elegancia, pues pese a su tibia y dispar acogida todos los críticos coincidieron en subrayar la elegancia de su autor. Una puta elegante.

\section{Historical Architecture is really "in"}

Como era de esperar, la crítica mostró en su reacción inmediata a la obra un cierto despiste ante el cambio de tercio. La lectura más habitual sería la reflejada por Andrea Dean, quien al reseñarla en el Journal of the American Institute of Architects, la valora como obra clásica, "especially in its Byzantine plan". Excepciones, como Robin Boyd, la sitúan a modo de interesante muestra de un cambio de tornas en la arquitectura (Boyd 1966:149-150).

Con el paso de los años, y posmoderno mediante, siguió sin comprenderse del todo. Peter Blake, autor de la recopilación de la obra de Johnson para Birkhaüser en 1996 insiste en que el pabellón no le resulta del todo convincente, valorándolo como obra moderna 'a pesar de': "It's a modern building? Of course - despite it's debts to Sinan`s Mosques" (Blake 1996:88). Su lectura es del todo errónea. La obra es moderna 'gracias a' Borromini, a Lutyens, a Sinan....a Mies.

Con el cambio de siglo, y a medida que la luz de Johnson se apagaba para dejar paso a los focos de los homenajes, surgieron nuevos apoyos. En estos se irán alternando ligeras criticas desde el cariño y el respeto, como la de Lewis \& O Connor: "slightly the wrong scale. The roof is low, the columns so large that they are more objects than supports" (Lewis, O'Connor 1994:52) con alegatos ciegos como los de Peter Eisenman (1977:12; 1996:56-57).

El más radical es sin duda el de Mark Wigley, para el que la falta de interés que 
Fig 19. Aires Mateus, Proyecto Escuela de Arquitectura de Tournai $2014 \&$ Snøhetta, Boat House. Hudøy, Norway, 2014. Dumbarton Oaks Library Washington $D C$.

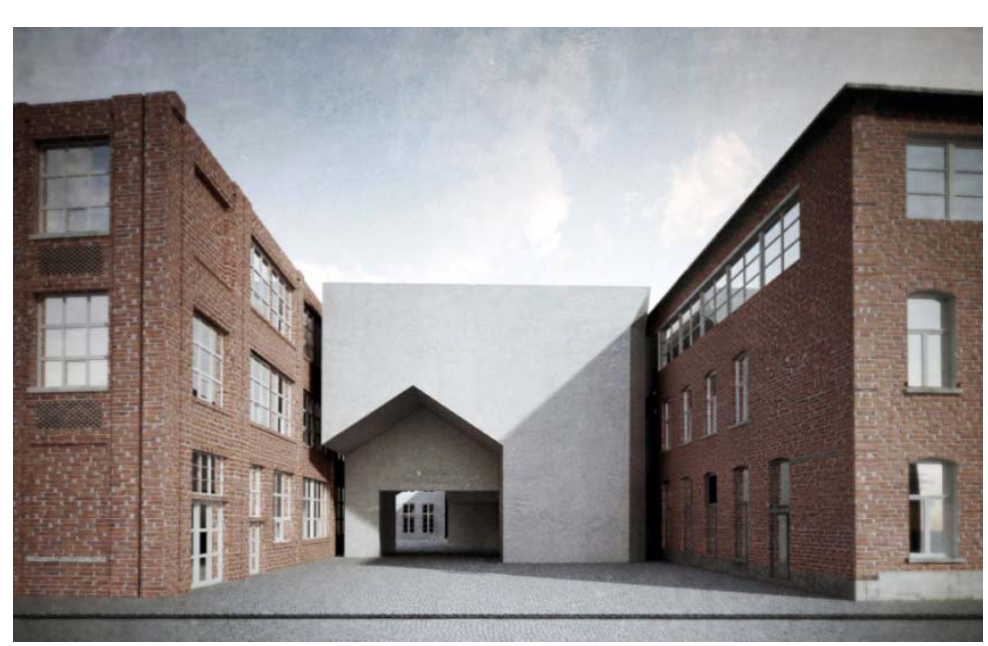
formas en el que Mies y Soane son enlazados a la perfección por Johnson (Wigley 2009:216-17).

En magnificos ejemplos de arquitecturas recientes detectamos intereses cercanos: la geometría recogida y manipulada por

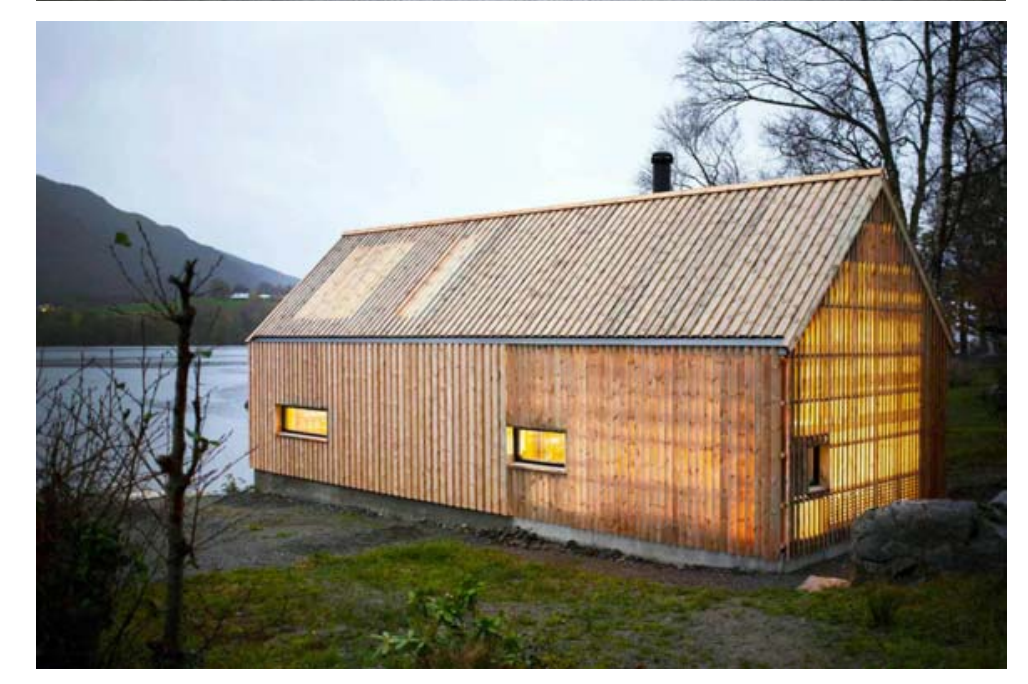

suscitó el Pabellón tiene una clara explicación, el miedo a la seducción: "Our fear of this work, and I believe it is a fear, is a fear of seduction by that which lies just outside the rules, outside the law" (Wigley 2009:217).

Wigley emplea un atractivo juego retórico para calificarla: "a reaction to people's reaction to the reaction to Mies." Para él, podría ser la pieza clave en la evolución de la modernidad: "What, for example, if the rarely discussed Dumbarton Oaks extension of 1963 is the key work?" En su respuesta alude a la paradójica condición de una planta demasiado simple que encierra un interior demasiado elaborado, demasiado 'dorado'. Al calificar la obra como "erotic refrigerator" pretende hacernos ver cómo en el joyero se combinan la frialdad moderna con la sensualidad y el refinamiento clásicos, en un sugerente juego de
Eisenmann; los arquetipos rescatados por Aires Mateus; las pautas de orden de la obra de Rafael Moneo; o el aprendizaje del acercamiento vernáculo al paisaje de Snøhetta, entre otros, permiten afirmar, parafraseando a Johnson, que "Historical architecture is "in" (Johnson 1979b), que la Historia sigue siendo una valiosa caja de herramientas.

\section{Notas}

1. "I am a whore": Philip Johnson at eighty by Diana Ketchum. Architecture December 1986

2. Su padre, geólogo y escritor, conquistó primero la riqueza a través de la patente de un laxante infantil (Fletcher's Castoria) y más tarde la política al ser elegido congresista por New York.

3. Mildred ejercía desde 1935 de consejera del MoMa. La amistad de Johnson con Kirstein comenzó en los años 20 cuando ambos coincidieron en Harvard. Sobre su monumento Lincoln Kirstein Tower, construida en 1985 en New Canaan, Johnson declararia: Well, I admire Lincoln Kirstein. He is a great poet and a great citizen and he's founded a great institution ...Each person will have to go for himself and read it." Entrevista realizada en 1991 por E. Devens, F. Schultz, J. Shaw, and F. Sanchis para el National Trust for Historic Preservation.

4. carta Thacher a Bliss 28 de mayo de 1959

5. John Seymour Thacher, director de Dumbarton Oaks hasta 1969, sucumbió inmediatamente a los encantos de un proyecto que la Comisión del Museo había valorado como inapropiado. Carta de Thacher a Bliss, Junio 59

6. http://www.historicaerials.com. Las fotografias aéreas de 1951 revelan su existencia.

7. JOHNSON, P., Planta de la ampliación del Museo de Dumbarton Oaks, 27 Agosto 1959. (AR.AP.MW.PC.001). La ampliación se localiza al sur del Museo existente, en la fachada a la calle 32.

8. En los planos del proyecto ejecutivo de 1960 la topografia y la posición del arbolado aparecen ya perfectamente reflejados e incluso, posteriormente, se elaboraron planos especificos durante la obra para la protección de algunos ejemplares de árboles cercanos a la excavación.

9. Según él, el patrimonio andaluz se encontraba en aquel momento sobrevalorado y expoliado por las armas de los franceses y el dinero de sus compatriotas. p 491, 509.

10. (carta Thacher 2 sept 59).

\section{Bibliografia}

Blake, P. 1996. Philip Johnson. Basel; Boston: Birkhäuser Verlag.

Boyd, R. 1965. The Puzzle of Architecture. Carlton, Australia] Melbourne University Press; New York, Cambridge University Press.

CоOK J.W., KLOTZ, H. 1973. Conversations with Architects. New York: Praeger.

CARDER, J. N. 2011. Philip Johnson at Dumbarton Oaks. Washington: Dumbarton Oaks Museum.

Devens, E., Schultz, F., Shaw, J. y Sanchis, F. Entrevista realizada en 1991 para el National Trust for Historic Preservation.

Eisenman, P. 1977. Behind the Mirror: On the Writings of Philip Johnson. Oppositions 10:12. 
Eisenman, P. 1996. Is Philip Johnson the End of A Line?. ANY: Architecture New York, Issue 90: 56-57.

Gropius, W. 1954. Eight steps toward a solid architecture. Architectural Forum, Feb. 1954, vol. 100, 2: 156-157

HITCHCOCK, H.R. The International Style Twenty Years Later. Architectural Record, 110, August 1951: 89-97.

Johnson, P. 1955. The Seven Crutches of Modern Architecture. Perspecta vol 3: 40-45. Yale University Press.

Johnson, P. 2001. Foreword: The Pavilion in the Garden. En: Tamulevich, S. Dumbarton Oaks, Garden Into Art. New York: Monacelli Press. 18-20.

Johnson, P. 1979. The puzzle of Architecture. En: Writings. New York: Oxford University Press: 130-135.

Johnson, P. 1979. What makes me tick. En: Writings. New York: Oxford University Press. 261-266.

Johnson, P. 1979. Whiter Away - Non-Miesian Directions. En: Writings. New York: Oxford University Press. 230-234.

LAMBERT, P. 2009. Philip Johnson: Breaking with Modernism. The "whence \& whithe" of it. En: Petit, E. (ed.), Philip Johnson: The constancy of change. New Haven: Yale University Press. 190-207.

LEWIS, H., O'Connor, J. 1994. Philip Johnson, The Architect in His Own Words. New York: Rizzoli International Publications.

Rodman, S. 1957. Conversations with Artists. New York: Capricorn Books.

SAARINEN, E, 1953. The Six Broad Currents of Modern Architecture. Architectural Forum. July vol 99,1: 110-115.

Scully, V. 2009. Philip Johnson: art and irony. En: Petit, E. (ed.), Philip Johnson: The constancy of change. New Haven: Yale University Press. 1837.

Stern, R. 2009. Foreword. En: Petit, E. (ed.), Philip Johnson: The constancy of change. New Haven: Yale University Press. vii-viii.

TANKARD, J. B. 2009. Beatrix Farrand: private gardens, public landscapes. New York: Monacelli Press.

TAmulevich, S. 2001. Dumbarton Oaks, Garden Into Art. New York: Monacelli Press.

TYLER, R, 1909. Spain, a study of her life and arts. New York, M. Kennerley; London, G. Richards.

VYAS, U. 2009. Philip Johnson and the rhetoric of the new: Panta Rhei versus the avant-garde. En: Petit, E. (ed.), Philip Johnson: The constancy of change. New Haven: Yale University Press. 230-233.

Vyas, U. 1996. The Intellectual Foundations of Philip Johnson, PhDisertation.

Wigley, M. 2009. Reaction Design. En: Petit, E. (ed.), Philip Johnson: The constancy of change. New Haven: Yale University Press. 208-19.

Kertchum, D. 1986. Philip Johnson at eighty. The New Criterion, December.

https://www.newcriterion.com/articles.cfm/-I-ama-whore--Philip-Johnson-at-eighty-6103 "I am a whore"

\section{Fuentes documentales}

Dumbarton Oaks Research Library and Collection. Sección Precolumbian Pavilion Plans Drawings. Sección Correspondence. Carta Thacher a Bliss 28 de mayo de 1959. Carta Thacher a Johnson, 2 sept 59. Carta de Thacher a Bliss, Junio 59.
Fecha final recepción articulos: 30/04/2017

Fecha aceptación:

08/07/2017

Articulo sometido a revisión por dos revisores independientes por el método doble ciego. 